\title{
Effect of a porcine circovirus type 2 infection on embryos during early pregnancy
}

\author{
B. Mateusen ${ }^{\mathrm{a}}$, D.G.D. Maes ${ }^{\mathrm{a}}$, A. Van Soom ${ }^{\mathrm{a}, *}$, D. Lefebvre ${ }^{\mathrm{b}}$, H.J. Nauwynck ${ }^{\mathrm{b}}$ \\ ${ }^{a}$ Department of Reproduction, Obstetrics and Herd Health, Ghent University, Faculty of Veterinary Medicine, \\ Salisburylaan 133, 9820 Merelbeke, Belgium \\ ${ }^{\mathrm{b}}$ Laboratory of Virology, Ghent University, Faculty of Veterinary Medicine, Salisburylaan 133, 9820 Merelbeke, Belgium
}

Received 22 February 2007; received in revised form 19 June 2007; accepted 14 July 2007

\begin{abstract}
The aim of the present study was to assess the effects of porcine circovirus type 2 (PCV2) on porcine embryos and their receptor sows during the first 21 days of pregnancy. Hatched blastocysts exposed to $10^{5.0}$ TCID $_{50}$ PCV2 per ml (strain 1121, fifth passage PK15) and negative control embryos were transferred to PCV2-immune receptor sows at the 7th day of the cycle. Two weeks after transfer (D21), the receptor sows were euthanized and embryos were recovered. They were assessed macroscopically for viability and examined for viral antigen-positive cells by immunoperoxidase staining. The embryonic survival rate of the PCV2-exposed embryos $(6.4 \%, 7$ viable embryos out of 110 transferred) was significantly lower than the survival rate of the negative control embryos $(65.4 \%, 34$ viable embryos out of 52 transferred). All of the non-viable PCV2-exposed embryos $(n=9)$ displayed immunohistochemical positive signals for PCV2-antigen in degenerated tissues. In the PCV2-exposed embryos that were categorized as viable at D21, small clusters $(n=4)$ or no PCV2-positive cells $(n=3)$ were detected. The pregnancy results of the receptor sows that received PCV2-exposed embryos (1/5) were considerably different from the negative control receptors (2/2), with 3 out of 5 sows displaying a regular return to oestrus.

In conclusion, it can be stated that PCV2 can replicate in embryos and might lead to embryonic death. In a small proportion of embryos, PCV2 exposure does not have a detrimental effect on embryo development before D21.
\end{abstract}

(C) 2007 Elsevier Inc. All rights reserved.

Keywords: PCV2; Porcine embryo; Embryo transfer

\section{Introduction}

Porcine circovirus type 2 (PCV2) is a widespread, circular, single-stranded DNA virus, recognized as the causal agent of post-weaning multisystemic wasting syndrome (PMWS) [1]. This syndrome, associated with substantial economic losses in the pig industry worldwide, is clinically characterized by wasting, paleness of the skin and increased mortality in weaned

\footnotetext{
* Corresponding author.

E-mail address: ann.vansoom@ugent.be (A. Van Soom).
}

pigs. PCV2 infection of pregnant sows can also cause fetal death leading to mummification or late-term abortion. Several field reports have described the detection of PCV2-antigens mainly in heart lesions of aborted or mummified fetuses from swine herds that were recently primary infected with PCV2 [2-5]. Intrafetal inoculation experiments with PCV2 in different fetal stages of development confirmed its pathogenic capacity in fetal tissues [6-8]. Recently, transplacental spread of PCV2 leading to abortion was also experimentally induced after intranasal inoculation of sows serologically negative for PCV2 at 92 days of gestation [9]. 
In general, next to transplacental spread after viraemia, viral contamination of female or male gametes can also induce a vertical transmission of virus. For PCV2, using nested PCR assays, viral DNA was demonstrated in $11 \%$ of the cumulus oocyte complexes of sows with PCV2-antibodies [10] and intermittently in semen samples of experimentally and naturally infected boars [11-13]. Research on the infectivity of these contaminated gametes is limited. In an experimental model, mimicking the effects of using PCV2-contaminated semen, Cariolet et al. [14] were able to cause a vertical transmission of PCV2 after intrauterine insemination of virus-spiked semen. This resulted in virus replication in fetal stages of development leading to fetal death and mummification. Previous work of our group has shown that the zona pellucida forms a barrier against PCV2 infection. Posthatching, PCV2 can infect porcine blastomeres after in vitro virus incubation. However, no influence on in vitro embryo development and no degenerative processes could be detected during a $48 \mathrm{~h}$ period following virus inoculation [15]. This raises concerns for the risk of virus transmission through embryo transfer since morphological criteria that are used to select transferable porcine embryos cannot distinguish PCV2-infected from PCV2-free morulae and blastocyts. To date, it is unknown which effects PCV2 infection of embryos may have further on during pregnancy. The aims of this study were to investigate the effect of transferring PCV2exposed porcine embryos on (i) viability and extent of infection of the embryos at 14 days after transfer, and (ii) pregnancy results of sows.

\section{Materials and methods}

\subsection{Collection of in vivo derived porcine embryos}

A total of 25 multiparous (parity 2-5), PCV2infection immune sows (Rattlerow-Seghers sows) were used in the present study. The sows were superovulated using PMSG (Folligon ${ }^{\circledR} 1500 \mathrm{IU}$ im) 3 days after weaning, followed by hCG (Chorulon ${ }^{\circledR} 1500$ IU im) $72 \mathrm{~h}$ later. The sows were fixed-time inseminated with boar semen of Piétrain boars of proven fertility, $24 \mathrm{~h}$ after hCG administration and slaughtered 6 days postinsemination. The reproductive tracts were removed and transported to the laboratory in a pre-warmed box $\left(39{ }^{\circ} \mathrm{C}\right)$ within $30 \mathrm{~min}$ after slaughter. The uterus was flushed with $500 \mathrm{ml}$ of Dulbecco's PBS supplemented with $2 \%$ foetal bovine serum (FBS). After 10 washings [16], blastocysts $(n=235)$ were cultured in NCSU-23 [17] supplemented with $2 \%$ foetal bovine serum (FBS) at $39{ }^{\circ} \mathrm{C}$ in $5 \% \mathrm{CO}_{2}$ in air for $24 \mathrm{~h}$ until they reached the hatched blastocyst stage $(n=212)$.

\subsection{Porcine circovirus type 2 (PCV2) exposure}

PCV2 strain 1121 was used for inoculation. It was originally obtained from a pool of lungs, liver and spleen of dead fetuses/piglets at partum [2] and further passaged five times in PK-15 cells. The hatched blastocysts were placed in $1 \mathrm{ml}$ of minimum essential medium (MEM), containing $10^{5.0}$ tissue culture infectious doses $50 \%$ end point $\left(\mathrm{TCID}_{50}\right)$ and incubated for $1 \mathrm{~h}$ at $39{ }^{\circ} \mathrm{C}$ in an atmosphere of $5 \% \mathrm{CO}_{2}$ in air. Negative control embryos were incubated under the same circumstances in MEM without PCV2. After $1 \mathrm{~h}$ of exposure, all embryos were washed 10 times in NCSU-23 medium and divided at random in groups of approximately 23 embryos, which were put into straws. As positive controls, embryos incubated with PCV2 were cultured at $39{ }^{\circ} \mathrm{C}$ in $5 \% \mathrm{CO}_{2}$ in air for $48 \mathrm{~h}$, fixed in $4 \%$ paraformaldehyde and examined for PCV2-antigens using indirect immunofluorescence (IIF) [15].

\subsection{Experimental design}

Hatched blastocysts $(n=182)$ were surgically transferred as described by Hancock and Hovell [18] on the 7th day of the cycle to a total of eight synchronised PCV2-infection immune sows. Donor and receptor sows had been vaccinated against porcine parvovirus, Erisopelothrix rhusiopathiae and pseudorabies virus. On average 23 embryos were transferred per sow. Five receptor sows received hatched blastocysts that were PCV2-exposed, whereas three control sows received negative control embryos. After the embryo transfer, sows were clinically evaluated (general condition, rectal temperature and appetite) on a daily basis for 14 consecutive days after which the sows were euthanized and their genital tracts examined. Uteri were opened and embryos were collected and scored macroscopically. Embryonic remnants lacking the normal morphologic structure of a porcine embryo 21 days after insemination were categorized as non-viable. A sow was defined as being pregnant when viable embryos were recovered from the uterus. An embryonic survival rate of a sow was defined as the number of viable embryos collected at D21 divided by the number of transferred embryos at D7. Serum samples from receptor sows were taken the day of the embryo transfer and 14 days later and tested for antibodies against PCV2 using an immunoperoxidase monolayer assay (IPMA) as described by Labarque et al. [19]. 


\subsection{Detection of viral antigen expression in day 21 embryos}

Embryos were fixed in $4 \%$ paraformaldehyde, embedded in paraffin and sections were made with intervals of $15 \mu \mathrm{m}$. Immunoperoxidase staining was performed to detect PCV2-positive cells. Slides were suspended in a sodium citrate buffer solution before being placed in a microwave of $800 \mathrm{~W}$ for antigen retrieval. After being rehydrated in ethanol solutions $(100 \%, 95 \%, 70 \%$ and $50 \%)$ slides were washed with a TRIS buffer solution. Subsequently, slides were incubated in a TRIS buffer with sodium azide (10\%) and hydrogen peroxide $(0.5 \%)$ to block the endogenous peroxidase activity. Following three 5 min washes in a TRIS buffer, slides were incubated for $1 \mathrm{~h}$ at $39^{\circ} \mathrm{C}$ with a 1:100 dilution of PCV2 monoclonal antibody (F190) [20]. Monoclonal antibody 13D12, directed against pseudorabies virus protein $\mathrm{gD}$ [21] was used as a control. Afterwards, slides were washed with TRIS, incubated for $1 \mathrm{~h}$ with biotinylated goat-anti-mouse secondary antibodies (Dako, Denmark) and washed again with TRIS. Next, the slides were incubated for half an hour with streptavidin-biotin HRP solution (Dako, Denmark). The reaction was visualized with 3,3'-diaminobenzidine (Dako Liquid DAB plus, Dako, Denmark). A haematoxylin-eosin staining was performed to identify organs and degenerative processes. After mounting the embryos in glycerol with 1,4diazabicyclo (2.2.2) octane $(25 \mathrm{mg} / \mathrm{ml})$, embryonic structures and organs were evaluated for antigenpositive signals using a Leica DM/RBE fluorescence microscope at a magnification of $400 \times$ and $600 \times$.

\subsection{Statistical analysis}

Antibody titres against PCV2 of the receptor sows were compared between the two groups of sows at the day of ET (D7) and 14 days after ET (D21) using a
Kruskal-Wallis test. Differences in pregnancy results and the ratio of viable embryos between the two groups of sows was analyzed using Chi-square analysis. Fisher's exact tests were applied when small numbers were involved. Variables were considered to be significant at a 0.05 level (two-sided). The statistical analyses were performed using SPSS (SPSS 14, SPSS Inc., Illinois, USA, 2006).

\section{Results}

\subsection{Clinical monitoring and antibody titres against PCV2 of receptor sows}

None of the receptor sows developed clinical signs in the 2-week period following the embryo transfer. One sow belonging to the control group was injured the day of embryo transfer and became lame. For that reason, she was taken out of the experiment. The antibody titres against PCV2 the day of ET and 14 days later were similar for negative control sows and sows that had received PCV2-exposed embryos. Also, none of the sows showed any rise in antibody titres against PCV2, 14 days after ET.

\subsection{Pregnancy results after embryo transfer}

The two sows that received negative control embryos were pregnant 14 days after ET (A and B). They contained viable embryos and had active corpora lutea. In two out of the five sows that received infected embryos, embryos and corpora lutea were detected $(C$ and D). However, the embryos of sow D were not viable and therefore the sow was designated as not pregnant. The remaining three sows that had received PCV2exposed embryos were not pregnant (E, F and $G$ ). Embryos were not found and the sows had follicles of 6-10 $\mathrm{mm}$ in diameter without any corpora lutea on the ovaries. These sows also displayed early oestrous symptoms 14 days after ET.

Table 1

Results of embryo transfers using negative control or PCV2-exposed embryos

\begin{tabular}{lllccc}
\hline Sow & $\begin{array}{l}\text { Transferred } \\
\text { embryos }\end{array}$ & $\begin{array}{l}\text { Number of transferred } \\
\text { embryos at D7 }\end{array}$ & $\begin{array}{l}\text { Number (\%) of recovered } \\
\text { embryos at D21 }\end{array}$ & $\begin{array}{l}\text { Number (\%) of viable } \\
\text { embryos at D21 }\end{array}$ & $\begin{array}{l}\text { Number (\%) of non-viable } \\
\text { embryos at D21 }\end{array}$ \\
\hline A* & Negative control & 20 & - & - & - \\
B & Negative control & 26 & $19(73)$ & $19(73)$ & $0(0)$ \\
C & Negative control & 26 & $17(65)$ & $15(58)$ & $2(8)$ \\
D & PCV2-exposed & 20 & $13(65)$ & $7(35)$ & $6(30)$ \\
E & PCV2-exposed & 23 & $3(13)$ & $0(0)$ & $3(13)$ \\
F & PCV2-exposed & 20 & $0(0)$ & $0(0)$ & $0(0)$ \\
G & PCV2-exposed & 18 & $0(0)$ & $0(0)$ & $0(0)$ \\
H & PCV2-exposed & 29 & $0(0)$ & $0(0)$ & $0(0)$
\end{tabular}

Sow $\mathrm{A}^{*}$ was taken out of the experiment because she showed severe lameness the day after ET. 


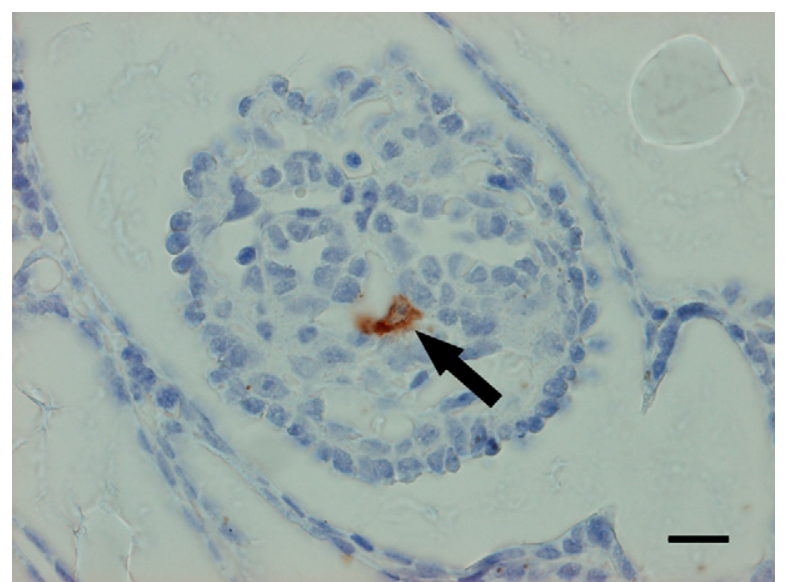

Fig. 1. Detection of porcine circovirus type 2 (PCV2) viral antigens by immunoperoxidase staining (brown) in a mesonephros cell of a D21 porcine embryo. Magnification $=600 \times$; bar $=25 \mu \mathrm{m}$.

\subsection{Macroscopic scoring of embryos 14 days after ET (Table 1)}

A significantly lower embryonic survival rate was detected in sows that had received PCV2-exposed embryos $(6.4 \%, 7 / 110)$ compared to the survival rate in the negative control sows $(65.4 \%, 34 / 52)(P<0.05)$ Table 1.

\subsection{Histological and immunohistochemical assessment of embryos}

All 30 positive control embryos that were examined by IIF $48 \mathrm{~h}$ after PCV2 incubation had PCV2-positive cells (on average $5.3 \%$ per embryo). None of the embryos collected from negative control sows showed PCV2-positive signals. It was impossible to distinguish different organs in the non-viable embryos since they were highly degenerated, but PCV2 antigens were detected in tissues of all non-viable embryos collected from sows that had received PCV2-exposed embryos. In four out of the seven viable embryos recovered from sows that received PCV2-positive embryos, individual or small clusters of PCV2-positive cells were detected in the placenta (2/4), the mesonephros (2/4, Fig. 1), the neural tube and the liver (2/4). In the remaining three viable embryos, PCV2-positive signals were not detected.

\section{Discussion}

A number of studies have already used the porcine ET model to gain more insight in the effect of viruses on embryos and receptor sows $[22,23]$. In the present study, the virological and clinical outcome of transferring PCV2-exposed embryos was investigated on embryo and sow level. Results showed that a PCV2 infection of embryos can lead to embryonic death and subsequent pregnancy loss.

The embryonic survival rate of PCV2-exposed embryos $(6.4 \%)$ was significantly lower than that of the negative control embryos $(65.4 \%)$ which was comparable to common survival rates $(60 \%)$ after porcine surgical ET [24]. In three out of the five sows receiving PCV2-exposed embryos, major embryonic losses must have occurred before the 12th day of gestation because these three sows experienced a regular return to oestrus. Sows having less than four viable embryos in the uterus at the 12th day of the cycle will not maintain pregnancy and can return to oestrus around D21 [25]. Since preimplantation embryos before 14 days of age are totally resorbed within 5 days after embryonic death [26], it was impossible to detect or analyse any embryonic remnants of embryos that died before the 12th day of the cycle at the end of the experiment (D21). Although hard conclusions concerning the cause of these early embryonic deaths cannot be drawn, it is expected that PCV2 infection was involved.

In the two remaining sows that received PCV2exposed embryos and did not show a regular return to oestrus, a total of nine non-viable, degenerated embryos were found. In one of these sows, also seven viable embryos were collected. In all of the non-viable embryonic remnants, clusters of PCV2-positive cells were detected in degenerated tissues. In four out of the seven viable embryos, individual or small foci of PCV2positive cells without any gross histological lesions were detected in the placenta, the mesonephros, the neural tube and the liver. We could not detect any PCV2-positive signal in the three remaining viable embryos. There seems to be an individual difference in susceptibility of embryos for a PCV2 infection since in a small proportion of the embryos only minimal amounts or no antigen-positive cells were detected 14 days after virus inoculation. The embryos that were transferred to a receptor originated from different donor sows as they were randomly allocated to the receptors. This individual different susceptibility for PCV2 infection has already been described in foetuses and piglets by several authors [7,27]. Another possible explanation for the fact that three embryos became negative for viral antigens 14 days after transfer may be related to apoptosis, the process that embryos use during mammalian preimplantation development to eliminate unwanted or damaged cells [28]. Since $48 \mathrm{~h}$ after the virus inoculation only a small proportion of the 
blastomeres (on average 6\%) of the hatched blastocysts were infected [15], it is possible that through a confined apoptotical process this limited number of infected cells were expelled without any effect on further embryonic development [29]. Further research will focus on possible apoptotic effects PCV2 will have on embryos. The finding that four embryos had PCV2-positive cells in specific organs without producing excessive damage raises the question whether a persistent PCV2-infection of embryos can occur. In the present study, embryos were analyzed only 14 days after inoculation, which means that the time period was too short to really define the embryos as being persistently infected. A persistent viral infection may explain how PCV2 can cover the time period between the moment of intra-uterine inoculation at insemination and the start of pathology in several foetal stages of development as described by Cariolet et al. [14]. In this case, the factor that would trigger the increase in replication of PCV2 still remains to be identified.

The organ distribution of PCV2-positive cells in the viable embryos was different from that in foetuses and neonates where the heart and lymphoid tissues, respectively, were the main target organs [7]. It is known that in cell cultures, PCV2 requires actively dividing cells for replication [30]. Developing embryonic stages are full of mitotic activity, but only a few organs had PCV2-positive cells. This means that in embryos, next to the mitotic factor also other factors play a role in the replication of PCV2.

In the present study, immune receptor sows were used. They had high virus-antibody titres at the moment of embryo transfer. None of the receptor sows in the study showed clinical symptoms or seroconverted against PCV2 in the 14 days after ET. This suggests that the virus that was replicating in the embryos did not replicate in maternal tissues. This is in accordance with serological and clinical results after intra-uterine or intra-fetal inoculation of PCV2 where a serological response was never detected until 4 weeks after inoculation and where no clinical symptoms apart from fetal death and mummification were observed $[6,14]$. The pregnancy result after ET with PCV2exposed embryos (1/5) was considerably lower than the ET result using negative control embryos (2/2). The difference was not statistically significant due to the small numbers of receptor sows involved.

The results of the present study show that transferring PCV2-exposed embryos to PCV2-seropositive receptor sows affects pregnancy outcome. The replication of PCV2 in embryos before the 21st day of pregnancy leads to embryonic death in most embryos.
However, in some embryos no or only a limited number of PCV2-positive cells were detected 14 days after inoculation.

\section{Acknowledgements}

This work was partially funded by the European Union (Sixth Framework Programme, Project No. 513928, coordinated by Dr. Gordon Allan). The authors thank J. Ellis for kindly supplying the PCV2 isolate. They also thank Rattlerow-Seghers for providing the sows and acknowledge Kristof Van Damme, Stefaan Ribbens and Prof. W. van Den Broeck for their excellent assistance during the experiments.

\section{References}

[1] Allan GM, Ellis JA. Porcine circoviruses: a review. J Vet Diagn Invest 2000;12:3-14.

[2] West KH, Bystrom JM, Wojnarowicz C, Shantz N, Jacobson M, Allan GM, Haines DM, Clark EG, Krakowka S, McNeilly F, Konoby C, Martin K, Ellis JA. Myocarditis and abortion associated with intrauterine infection of sows with porcine circovirus 2. J Vet Diagn Invest 1999;11:530-2.

[3] Ladekjaer-Mikkelsen AS, Nielsen J, Storgaard T, Botner A, Allan G, McNeilly F. Transplacental infection with PCV-2 associated with reproductive failure in a gilt. Vet Rec 2001;148:759-60.

[4] O'Connor B, Gauvreau H, West K, Bogdan J, Ayroud M, Clark EG, Konoby C, Allan G, Ellis JA. Multiple porcine circovirus 2associated abortions and reproductive failure in a multisite swine production unit. Can Vet J 2001;42:551-3.

[5] Farnham MW, Choi YK, Goyal SM, Joo HS. Isolation and characterization of porcine circovirus type-2 from sera of stillborn fetuses. Can J Vet Res 2003;67:108-13.

[6] Sanchez Jr RE, Nauwynck HJ, McNeilly F, Allan GM, Pensaert MB. Porcine circovirus 2 infection in swine foetuses inoculated at different stages of gestation. Vet Microbiol 2001;83:169-76.

[7] Sanchez Jr RE, Meerts P, Nauwynck HJ, Pensaert MB. Change of porcine circovirus 2 target cells in pigs during development from fetal to early postnatal life. Vet Microbiol 2003;95:15-25.

[8] Yoon KJ, Jepsen RJ, Pogranichniy RM, Sorden S, Stammer R, Evans LE. A novel approach to intrauterine viral inoculation of swine using PCV type 2 as a model. Theriogenology 2004;61: 1025-37.

[9] Park JS, Kim J, Ha Y, Jung K, Choi C, Lim JK, Kim SH, Chae C. Birth abnormalities in pregnant sows infected intranasally with porcine circovirus 2. J Comp Pathol 2005;132:139-44.

[10] Bielanski A, Larochelle R, Algire J, Magar R. Distribution of PCV-2 DNA in the reproductive tract, oocytes and embryos of PCV-2 antibody-positive pigs. Vet Rec 2004;155:597-8.

[11] Larochelle R, Bielanski A, Muller P, Magar R. PCR detection and evidence of shedding of porcine circovirus type 2 in boar semen. J Clin Microbiol 2000;38:4629-32.

[12] Kim J, Han DU, Choi C, Chae C. Simultaneous detection and differentiation between porcine circovirus and porcine parvovirus in boar semen by multiplex seminested polymerase chain reaction. J Vet Med Sci 2003;65:741-4. 
[13] McIntosh KA, Harding JC, Parker S, Ellis JA, Appleyard GD. Nested polymerase chain reaction detection and duration of porcine circovirus type 2 in semen with sperm morphological analysis from naturally infected boars. J Vet Diagn Invest 2006; 18:380-4.

[14] Cariolet R, Blanchard P, Le Dimna M, Mahé D, Keranflec'h A, Jolly JP, Julou P, De Boisséson C, Mahé D, Madec F, Jestin A. Etude de différents modalités d'inoculation du circovirus porcin de type 2 PCV2 à des truies EOPS. Journées de la Recherche Porcine 2002;34:317-23.

[15] Mateusen B, Sanchez RE, Van Soom A, Meerts P, Maes DG, Nauwynck HJ. Susceptibility of pig embryos to porcine circovirus type 2 infection. Theriogenology 2004;61:91-101.

[16] Stringfellow DA. Recommendations for the sanitary handling of in-vivo-derived embryos. In: Stringfellow DA, Seidel SM, editors. Manual of the International Embryo Transfer Society. Savoy, IL: International Embryo Transfer Society; 1998 . p. 79-84.

[17] Petters RM, Wells KD. Culture of pig embryos. J Reprod Fertil Suppl 1993;48:61-73.

[18] Hancock JL, Hovell GJR. Egg transfer in the sow. J Reprod Fertil 1962;4:195-201.

[19] Labarque GG, Nauwynck HJ, Mesu AP, Pensaert MB. Seroprevalence of porcine circovirus types 1 and 2 in the Belgian pig population. Vet Quart 2000;22:234-6.

[20] McNeilly F, McNair I, Mackle DP, Meehan BM, Kennedy S, Moffett D, Ellis J, Krakowka S, Allan GM. Production, characterisation and applications of monoclonal antibodies to porcine circovirus 2. Arch Virol 2001;146:909-22.

[21] Nauwynck HJ, Pensaert MB. Abortion induced by cell-associated pseudorabies virus in vaccinated sows. Am J Vet Res 1992;53:489-93.
[22] Wrathall AE, Mengeling WL. Effect of transferring parvovirusinfected fertilized pig eggs into seronegative gilts. Br Vet $\mathbf{J}$ 1979;135:255-61.

[23] Bolin SR, Runnels LJ, Sawyer CA, Gustafson DP. Experimental transmission of pseudorabies virus in swine by embryo transfer. Am J Vet Res 1982;43:278-80.

[24] Youngs CR. Factors influencing the success of embryo transfer in the pig. Theriogenology 2001;56:1311-20.

[25] Polge C, Rowson LEA, Chang MC. The effect of reducing the number of embryos during early stages of gestation in the maintenance of pregnancy in the pig. J Reprod Fertil 1966;12: 395-7.

[26] Christianson WT. Stillbirths, mummies, abortions, and early embryonic death. Vet Clin North Am Food Anim Pract 1992;8: 623-39.

[27] Ladekjaer-Mikkelsen AS, Nielsen J, Stadejek T, Storgaard T, Krakowka S, Ellis J, McNeilly F, Allan G, Botner A. Reproduction of postweaning multisystemic wasting syndrome (PMWS) in immunostimulated and non-immunostimulated 3-week-old pigs experimentally infected with porcine circovirus type 2 (PCV2). Vet Microbiol 2002;89:97-114.

[28] Hardy K, Stark J. Mathematical models of the balance between apoptosis and proliferation. Apoptosis 2002;7:373-81.

[29] Mateusen B, Van Soom A, Maes DGD, Donnay I, Duchateau L, Lequarre AS. Porcine embryo development and fragmentation and their relation to apoptotic markers: a cinematographic and confocal laser scanning microscopic study. Reproduction 2005; 129:443-52.

[30] Allan GM, McNeilly F, Cassidy JP, Reilly GAC, Adair B, Ellis WA, McNulty MS. Pathogenesis of porcine circovirus: experimental infections of colostrum deprived piglets and examination of pig fetal material. Vet Microbiol 1995;44:49-64. 